\title{
Material flow control in plunge micro rotary swaging
}

\author{
Eric Moumi ${ }^{1,3^{*}}$, Philipp Wilhelmi ${ }^{1,3}$, Christian Schenck ${ }^{1,2,3}$, Marius Herrmann ${ }^{1,3}$ and Bernd Kuhfuss ${ }^{1,2,3}$ \\ ${ }^{1}$ bime, Bremen Institute for Mechanical Engineering, Badgasteiner Str. 1, 28359 Bremen, Germany \\ ${ }^{2}$ MAPEX Center for Materials and Processing \\ ${ }^{3}$ University of Bremen
}

\begin{abstract}
In rotary swaging, the material flow is not fully controlled by closure of the forming dies. This is especially noticeable in plunge rotary swaging of rod, where the workpiece is positioned into the forming zone und processed locally. As result, an uncontrolled elongation of the workpiece in axial direction takes place and an axial position shift of the workpiece relative to the dies occurs. This is a special challenge in production of linked micro parts, where single parts are interconnected in order to enable the handling as a strip and thereby a roll-to-roll production. The axial shift influences not only the subsequent positioning of neighbouring parts, but also the final geometry of the currently processed part. The presented investigation analyses the material flow during plunge micro rotary swaging on basis of in-process measurements of the workpiece shift on both sides of the forming zone as well as with the help of contour measurements of the processed parts. It is shown that the measured shift is strongly influenced by the workpiece clamping and fixation and that it can be controlled by applying low axial forces to the workpiece on one or both sides of the forming zone. Further, the geometry of the workpiece can be affected by these measures.
\end{abstract}

Keywords: Metal forming, Process control, Geometry

\section{Introduction}

Rotary swaging is an incremental cold forming process typically applied to produce rotational symmetric parts. There are two main process variants, the infeed and the plunge rotary swaging. They differ mainly in the type and direction of the feed. While the workpiece is fed axially in infeed rotary swaging, the dies are radially fed during plunge rotary swaging [1]. In Figure 1 the principle of the plunge swaging process is presented.

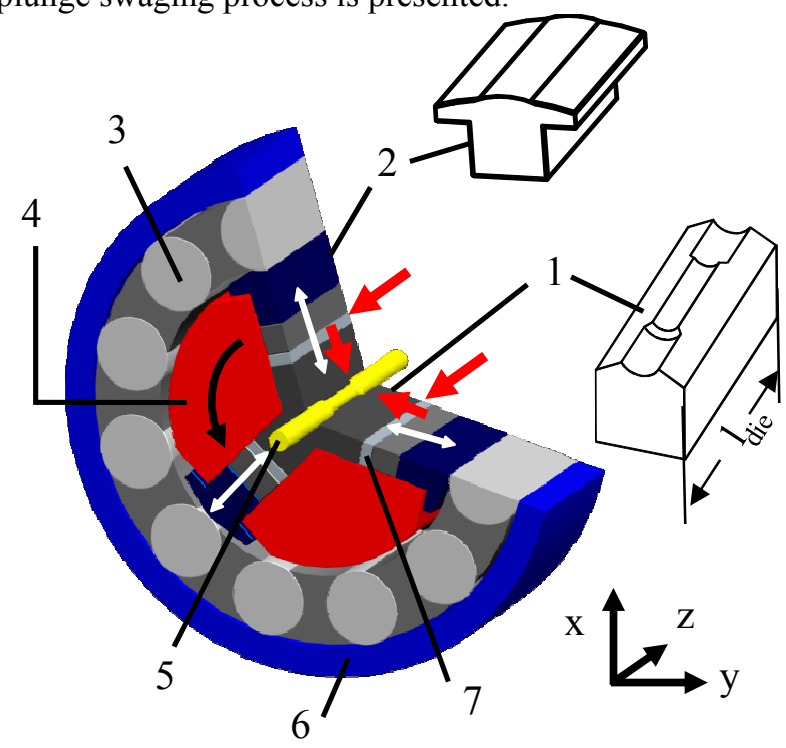

Fig. 1. Principle of plunge rotary swaging; 1 die, 2 base jaw, 3 cylinder roller, 4 drive shaft, 5 workpiece, 6 outer cage.
In plunge rotary swaging the workpiece is positioned in the forming zone between the dies. The swaging head in Figure 1 exhibits three dies, which process the workpiece locally. The forming of the workpiece takes place in the swaging head in small steps by radially oscillating motions and at a superposed radial feed of the dies towards the workpiece. The radial feed is realised with wedges (position 7 in Fig. 1). The radial oscillation of the forming dies (1) is generated by the rotation of the drive shaft (4) and the use of base jaws with cam on the top (2). By means of the roll motion between the base jaws and the cylinder rollers (3), the dies are pushed inwards simultaneously and the cross section of the workpiece (5) is reduced with every overrunning of the cams. An outer cage (6) encloses the described machine components. The workpiece is typically clamped in a collet, which is mounted on a supply system.

As in all forming processes, the understanding of the material flow is essential for a successful process design. Material flow was analysed by the visioplasticity method and the plasticity theory. In the visioplasticity method, the application of a grid in the area of the workpiece to be investigated allows determining the path of the material by a comparison of the grid before and after forming. In that way, statements about the strain and the strain rate could be made $[2,3]$. With the improvements in the computational technology, finite element methods (FEM) had become state of the art for analysing forming processes. According to [4] planning of incremental bulk forming processes ideally requires extended process

\footnotetext{
* Corresponding author: moumi@bimde.de
} 
simulations for gathering information about the material flow and also further product properties. However, the required fine meshes for the incremental forming and the resulting computation times have complicated their application in many cases [5]. Further, due to size effects in micro range $[6,7]$ advanced input data are required to validate that classical simulation models.

Inadequate material flow may cause several process failures such as flash formation, break and torsion of the workpiece [8]. Furthermore, the geometrical accuracy of the workpiece can also be affected by the material flow as presented in $[9,10]$. From investigations on plunge rotary swaging of linked micro parts rupture and misalignment of the workpieces by inadequate material flow was found [11]. Linked parts are suitable in micro manufacturing because the single parts are kept interconnected through a process chain so that handling and transportation issues can be simplified. During the rotary swaging process material flows in axial direction, which causes an elongation of the workpiece. This elongation leads to a relative axial motion of the processed area with respect to the dies although the workpiece is clamped in a collet. This shift can cause geometrical deviations or even a rupture of the workpiece, which must be avoided. Therefore, understanding and controlling the material flow is essential for the design of a robust plunge micro rotary swaging process.

In this work, the influence of applying forces to the workpiece at both sides of the swaging machine in micro plunge rotary swaging was investigated. The evaluation was based on in-process measurements of the workpiece shift on both sides and on contour measurements of the produced parts.

\section{Set up and experimental procedure}

Forming experiments were conducted with annealed rods made of AISI-304 (X5CrNi 18-10) with an initial diameter $\mathrm{d}_{0}=1.5 \mathrm{~mm}$. The annealing ensured good formability. Before forming, the workpiece was lubricated with "Condocut KNR 22". The same lubricant was also used for continuously lubricating the components in the swaging head close to the dies. The stroke frequency and the radial feed rate were kept constant at $102 \mathrm{~Hz}$ and $0.05 \mathrm{~mm} / \mathrm{s}$. At the end of the forming, when the radial displacement of the dies was completed they re-opened immediately without any settling time.

The setup for forming experiments consisted of three areas (Figure 2): the areas in the front and in the back of the forming machine, in which sensors for measuring the workpiece shift were implemented, and the machine in which the forming took place. The axial shift of the workpiece in the front ( $\left.\mathrm{s}_{\text {front }}\right)$ and at the backside ( $\mathrm{s}_{\text {back }}$ ) during forming was measured with two laser triangulation sensors. The triangulation sensors provided a resolution of $0.15 \mu \mathrm{m}$ within a measuring range of $10 \mathrm{~mm}$. The sensors captured the motion of lightweight reflectors, which were fixed on the workpiece and were guided by sliding guides. Adding the absolute values of the shift yielded the total elongation $\Delta \mathrm{l}$ of the workpiece according to Equation 1.

$$
\Delta l=\left|s_{\text {back }}\right|+\left|s_{\text {front }}\right|
$$

Due to the configuration of the forming machine, the distance between the middle of the forming zone of the die and the reflector in the front side was $\mathrm{L}_{\mathrm{F}} \approx 48 \mathrm{~mm}$ at the beginning of the reduction and was about 10 times shorter than the distance $\mathrm{L}_{\mathrm{B}}$ to the reflector in the backside, which was bridged with a guiding tube.

The geometry of the die and the workpiece are illustrated in Figure 3. The states before (Figure 3 a)) and after forming (Figure $3 \mathrm{~b}$ )) are shown. The die featured a length of $1_{\text {die }}=40 \mathrm{~mm}$ and the forming zone $1_{\mathrm{f}}=20 \mathrm{~mm}$. The transition zone of the die was designed with an angle $\alpha=8^{\circ}$. As the dies reduced the cross section of the workpiece, its diameter changed from $d_{0}$ to $d_{1}$ and its length increased from $l_{0}$ to $l_{1}$. In order to ease the handling and to speed up the experiments $d_{1}$ was set to $1.2 \mathrm{~mm}$. However, selected measurements for a reduction from $\mathrm{d}_{0}=1.0 \mathrm{~mm}$ to $\mathrm{d}_{1}=0.8 \mathrm{~mm}$ with another die set delivered the same trends as described below. During this process, an angle occurred at the transition between deformed and the not deformed area of the workpiece.

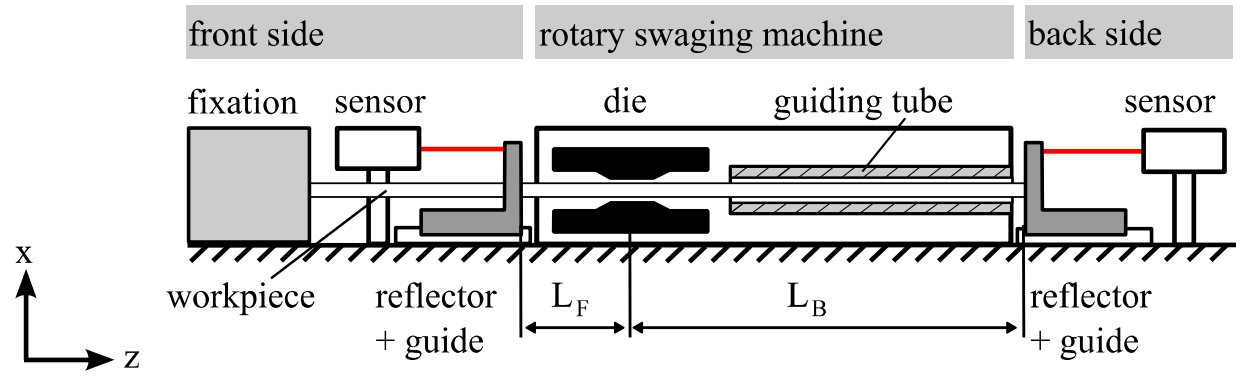

Fig. 2. Experimental setup. 

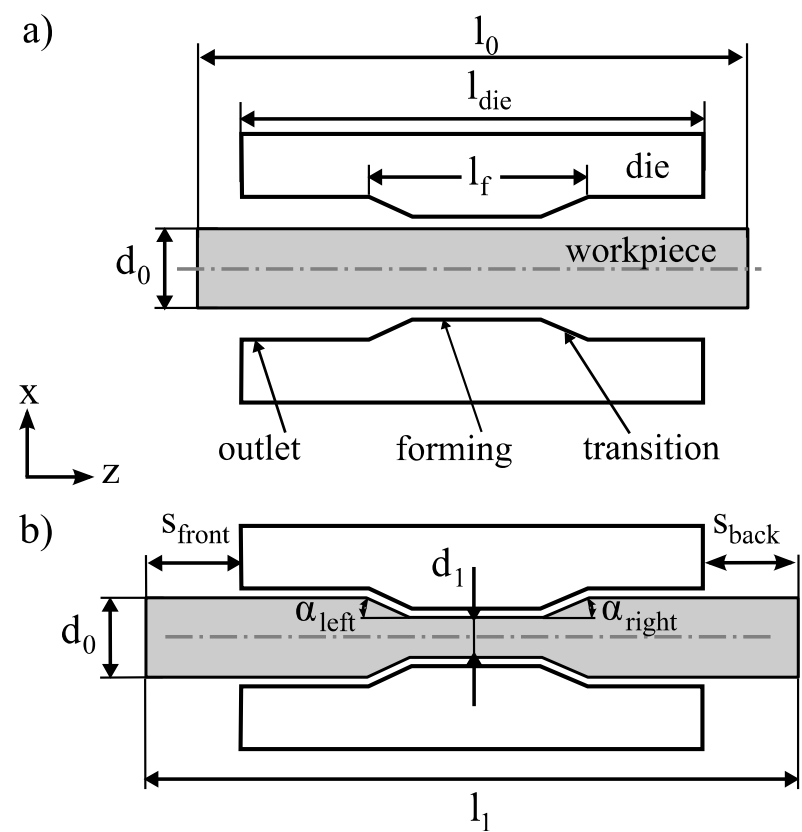

Fig. 3: Geometry of the dies and the workpiece; a) before forming, $b$ ) after forming.

To apply forces in axial direction of the workpiece helical springs were applied with four different set-up configurations (Figure 4):

A. Absence of external axial forces, no collet in use

B. Axial force in positive z-direction at the front; resembling a one-sided feed system

C. Axial force in negative $\mathrm{z}$-direction at the front; intermediate state to configuration $\mathrm{D}$

D. Axial forces at both sides away from the swaging head; symmetrical tensioning of the workpiece

no force

(A)

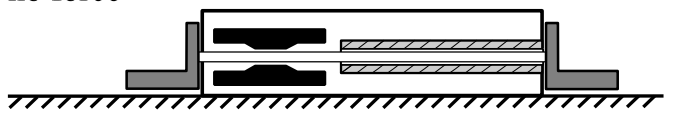

(B)

one-sided compressive force

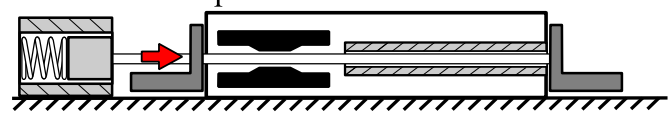

(C)

one-sided tensile force

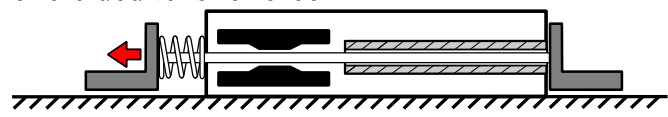

both-sided tensile force

(D)

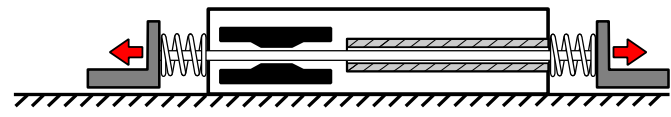

Fig. 4. Experimental setup configurations.

The applied helical springs featured a spring rate of $0.647 \mathrm{~N} / \mathrm{mm}$. The external forces were adjusted through appropriate preloading of the springs at the beginning of the forming process, Table 1. By the material flow, the springs were further compressed (configuration B) or stretched (configuration C and D) so that all forces changed almost proportionally with the shift.

Table 1. Axial forces for the four set-up configurations.

\begin{tabular}{|l|c|c|}
\hline $\begin{array}{c}\text { Name of } \\
\text { configuration }\end{array}$ & Type of axial forces & $\begin{array}{c}\text { Initial force } \\
\mathbf{F}_{\mathbf{a} \_ \text {initial }} \mathbf{( N )}\end{array}$ \\
\hline A & none & - \\
\hline B & $\begin{array}{c}\text { one-sided compressive } \\
\text { force }\end{array}$ & $0 ; 1.7 ; 3.6$ \\
\hline C & one-sided tensile force & 7.1 \\
\hline D & $\begin{array}{c}\text { both-sided tensile } \\
\text { force }\end{array}$ & 7.1 \\
\hline
\end{tabular}

Subsequently to the forming step, the final geometry of the workpiece was measured contactless with an optical micrometer. For that, the diameter of the workpiece was measured every $60^{\circ}$ around the z-axis and in $100 \mu \mathrm{m}$ steps in the same axis. For interpretation, the mean value of the diameter with respect to the z-position of each sample was considered.

\section{Results and Discussion}

\subsection{Axial shift of the workpiece}

For all experiments, the measured shifts were always negative in the front side ( $\mathrm{s}_{\text {front }} \leq 0$ ) and positive in the backside $\left(\mathrm{s}_{\text {back }} \geq 0\right)$.

\section{Configuration $A$}

In plunge micro rotary swaging with configuration A (no external axial forces) the material flowed freely in the front and in the back side. An exemplary measurement of the workpiece shift and the elongation during forming are shown in Figure 5.

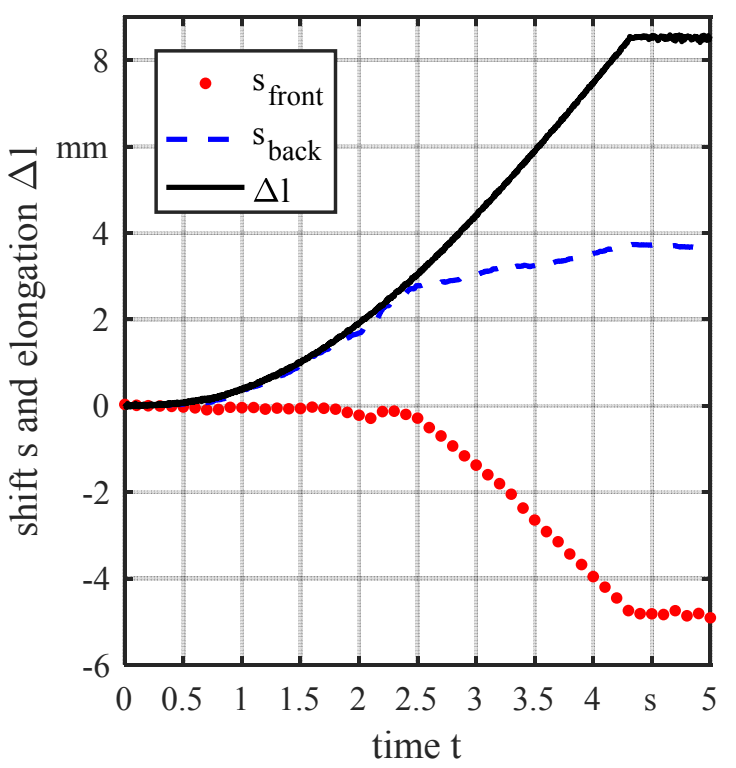

Fig. 5. Shift and elongation of workpiece \#3 during forming with configuration $\mathrm{A}$.

\footnotetext{
* Corresponding author: moumi@bimde.de
} 
Figure 6 shows the absolute values of the maximum shift in the front and at the backside as well as the elongation for five samples formed under same conditions. While the standard deviation of the elongation was less than $90 \mu \mathrm{m}$, it was higher than $500 \mu \mathrm{m}$ for the individually measured shifts. Additionally, the shift s was always higher in the front (Figure 6). As the workpiece was not fixed in axial direction, axial vibrations that were stimulated by the forming strokes changed the contact conditions between the workpiece and the dies. Hence, the workpiece could be shifted between the single strokes. The variation in the shifts could be attributed to the different lengths $\mathrm{L}_{F}$ and $\mathrm{L}_{\mathrm{B}}$. The longer length $\mathrm{L}_{\mathrm{B}}$ hindered the material flow to the backside due to friction forces in the guiding tube.

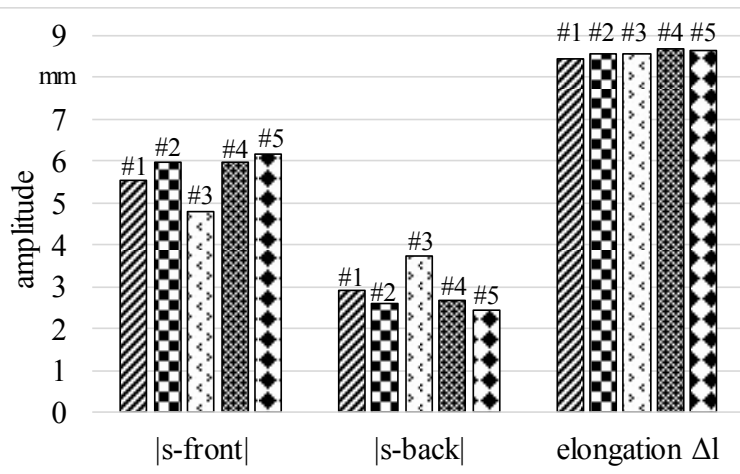

Fig. 6. Absolute shift and elongation for five samples during forming without external axial forces (configuration A).

\section{Configuration B}

In Figure 7, the shifts and the elongations for configuration $\mathrm{B}$ are presented as a function of the initial compressive force $\mathrm{F}_{\mathrm{a} \_ \text {initial. }}$.

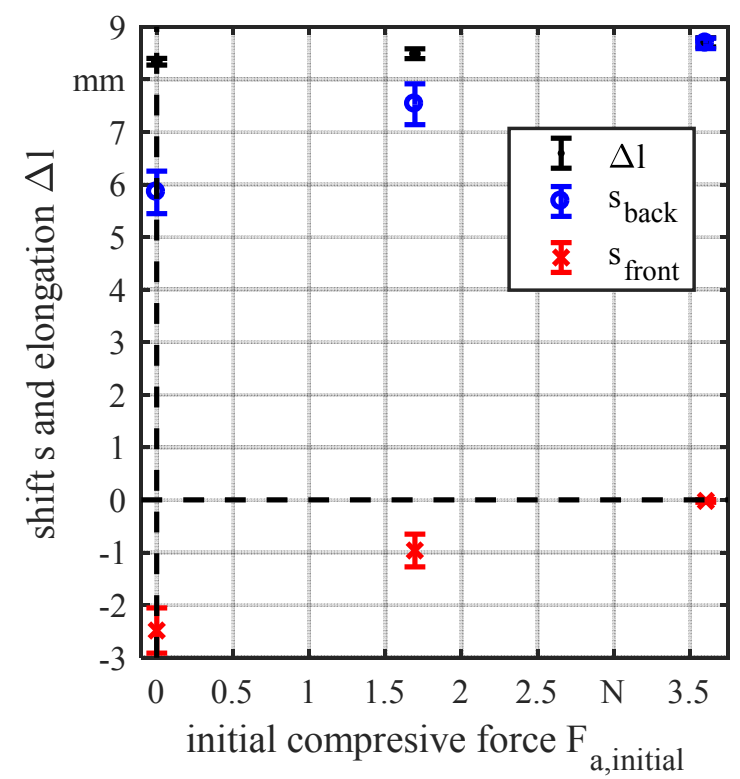

Fig. 7. Shift and elongation for different initial compressive forces (configuration B); mean values and single standard deviations.

Increasing the initial compressive force at the front side led to a reduction of the elongation in the negative $\mathrm{z}-$ direction and to a corresponding increase in the positive $\mathrm{z}$-direction. For the investigated initial compressive force of $0 \mathrm{~N}$ about $70 \%$ of the material shifted in positive $\mathrm{z}$ direction. Although the axial force rose with the shift, the results accord with configuration $\mathrm{A}$. With an initial force of $3.6 \mathrm{~N}$ the material shifted completely in positive $\mathrm{z}$ direction. Additionally, the scatter of the shift values is very low (standard deviation $<100 \mu \mathrm{m}$ ) when an initial force of $3.6 \mathrm{~N}$ was applied.

\section{Configuration $C$ and $D$}

In the configuration $\mathrm{C}$ and with an initial axial force value of $7.1 \mathrm{~N}$ the complete shift took place in the front side (Figure 8). This force value was high enough to direct the material flow completely in negative $\mathrm{z}$-direction.

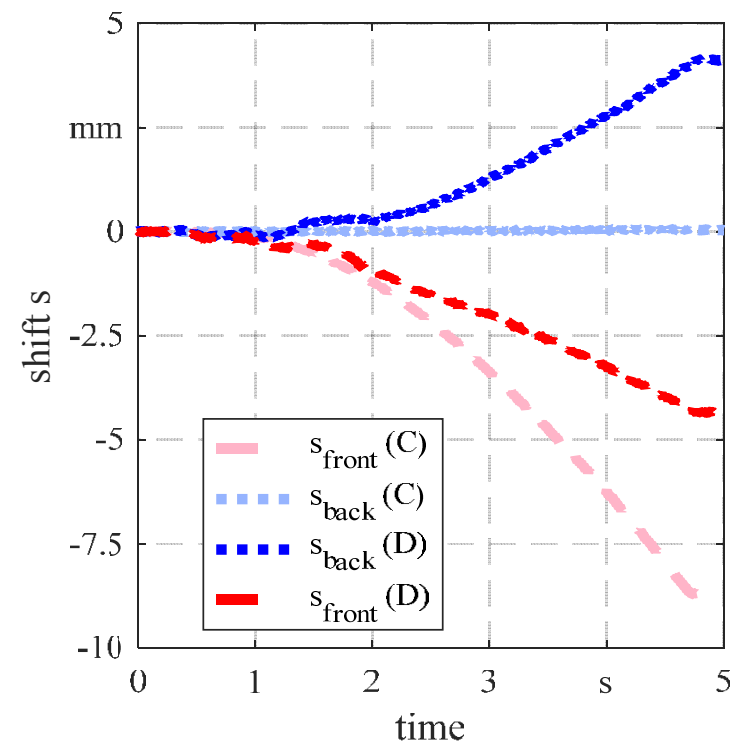

Fig. 8. Shift of the workpiece during forming with external oneand both-sided axial tension force (configurations $\mathrm{C}$ and $\mathrm{D}$ ).

Applying the symmetrical tensioning of the workpiece resulted in an almost equal shift in both directions. The shift at the front side was $-4.4 \pm 0.09 \mathrm{~mm}$ and at the back side $3.9 \pm 0.13 \mathrm{~mm}$. The difference between these values could be explained by the different distances from the forming zone to the measuring point of the triangulation sensors (Figure 2) and the friction in the guiding tube, as described above. The standard deviation of the total elongation was less than $100 \mu \mathrm{m}$.

\subsection{Workpiece Geometry}

Exemplary measurements for the resulting geometry are presented in Figure 9 together with the set geometry of the die. The contour of the workpiece changed with the kind and amplitude of the applied forces. It was found that the generated geometry significantly varied when no external force was applied. This coincides with the measured shifts. This low reproducibility can be explained by the uncontrolled motion of the workpiece in axial direction during the complete forming process (configuration A) or at the beginning of the forming (configuration $\mathrm{B}$, $\mathrm{F}_{\mathrm{a}_{\text {_initial }}}=0 \mathrm{~N}$ ). For the compressive force of $3.6 \mathrm{~N}$ in configuration B (Figure 9b) as well as for the one sided tensile force (Figure 9c) the geometrical deviation 
between tool and finished workpiece is concentrated to on side.
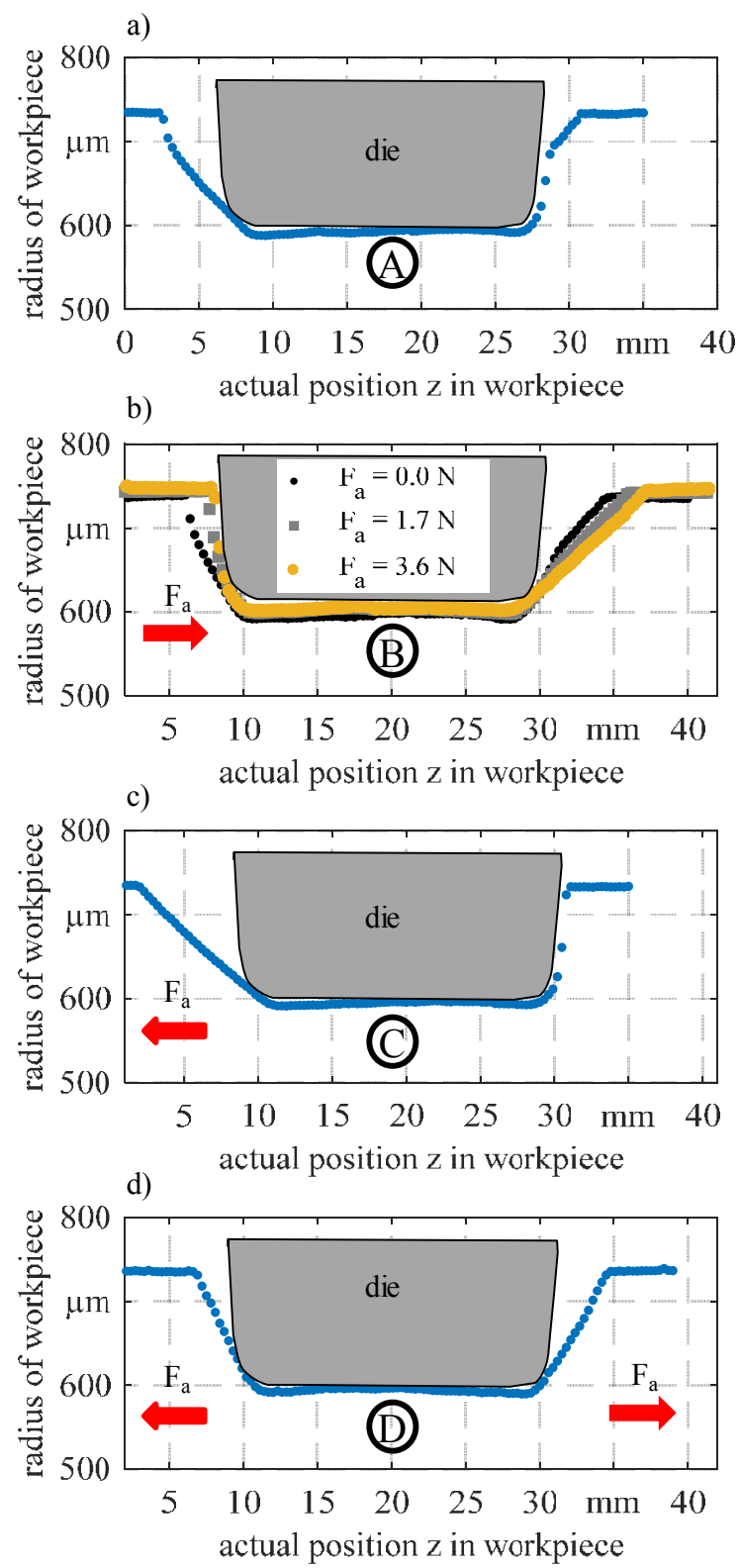

Fig. 9. Workpiece geometry for configuration; a) A, b) B, c) C, d) D.

On one side of the die, the contours of the workpiece and the die fit well and on the other side, contact occurs only in the base and the corner of the die and not anymore on the rising edge. With setting D (both-sides external axial tensile force (Figure $9 \mathrm{~d}$ )), this contact between tool and workpiece takes place only in the base of the die during the complete forming process.

To compare the geometry of the workpiece for different settings the symmetry value SYM was defined. This value is based on the relationship of angles on the left and the right side of the workpiece (Equation 2):

$$
S Y M=\frac{\alpha_{\text {left }}-\alpha_{\text {right }}}{\alpha_{\text {left }}+\alpha_{\text {right }}}
$$

SYM can take values between -1 and +1 . The case where the contour is symmetrical is represented by $\mathrm{SYM}=0$.
This characteristic value does not represent the actual geometry of the transition area between $d_{0}$ and $d_{1}$ in the workpiece but it shows the direction in which the material flow takes place. In addition, the reproducibility of the forming can be assessed. Figure 10 shows the SYM values of the four configurations and five samples each.

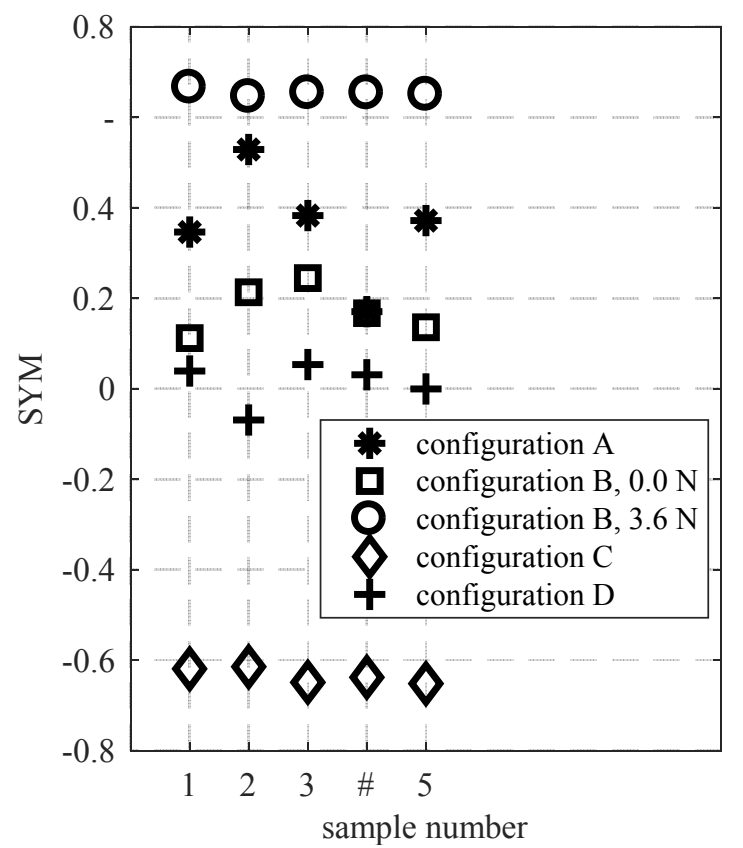

Fig. 10. Symmetry of the shift of the workpiece for different forming settings.

It can be noticed that for configurations A (no external axial forces) and $\mathrm{B}$ with a compressive force of $0 \mathrm{~N}$ the symmetry and therefore the material flow fluctuates strongly, $\quad \operatorname{SYM}(\mathrm{A})=0.36 \pm 0.13 \quad$ and $\operatorname{SYM}(\mathrm{B} 0.0 \mathrm{~N})=0.17 \pm 0.05$. That means manufacturing in those regimes will lead to less reproducibility of the geometry of the workpieces. On the other hand, forming with external axial forces can improve both the reproducibility and the part symmetry, the latter especially with configuration $\mathrm{D}$.

\section{Conclusion}

In the present study, experimental investigations for a better understanding of the material flow during plunge rotary swaging in micro range were performed. Measured axial shift of the workpiece during forming was correlated with the final workpiece geometry. The main results of the conducted experiments could be drawn:

- The final geometry of the workpiece reacts very sensitively on different external axial forces.

- Low forces at one side can ensure a constant touch between one side of the tool and the workpiece. This contact results in a one-sided imprinting of the tool geometry with high contour accuracy.

- A symmetrical forming is possible if equal tensile axial forces are applied on both sides of the forming zone. Thereby, the workpiece is kept in the same position and following stroke hit the same spot. 
The findings from the present investigation are particularly useful for the configuration of the forming in linked parts. As the external axial forces are another effective parameter to control the material flow, the influence on the resulting mechanical properties of the workpieces has also to be investigated. Furthermore, other processing parameters as the calibration time and the feed rate have to be varied, as well as different materials. The calculated standard deviations within this investigation were low, which indicates that size effects do not occur or have minor influence in micro rotary swaging. Thus, numerical process analysis with models that are validated in the macro range could be a possible measure to investigate the material flow in this micro-forming process.

\section{Aknowledgments}

The authors gratefully acknowledge the financial support by Deutsche Forschungsgemeinschaft (DFG, German Research Foundation) for the Subprojects A4 "Stoffverdrängen" and C5 "Teileverbunde" within the SFB 747 (Collaborative Research Center) "Mikrokaltumformen - Prozesse, Charakterisierung, Optimierung".

\section{References}

1. A. Uhlig, Ph.D. thesis, Technical University of Hannover (1964)

2. L. Chevalier, N. Dahan, J. Mat. Proc. Technol., 31, 1-2 (1992)

3. R. Paukert, K. Lange, CIRP Ann., 32, 1, (1983)

4. P. Groche, D. Fritsche, E.A. Tekkaya, J.M. Allwood, G. Hirt, R. Neugebauer, CIRP Ann., 56, 2, (2007)

5. G. Hirt, R. Kopp, O. Hofmann, M. Franzke, G. Barton, CIRP Ann., 56, 1, (2007)

6. F. Vollertsen, D. Biermann, H.N. Hansen, I. S. Jawahir, K. Kuzman, CIRP Annals Manuf. Tech. 58, 566 (2009)

7. X. Lai, L. Peng, P. Hu, S. Lan, J. Ni, Computational Materials Science, 43, 1003 (2008)

8. B. Kuhfuss, E. Moumi, V. Piwek, Procedings ICOMM2008, 86-91, (2008)

9. P. Wilhelmi, E. Moumi, E. Foremny C. Schenck, B. Kuhfuss, Proceedings of Newtech Conference, 75 (2013)

10. P. Wilhelmi, E. Moumi, C. Schenck, B. Kuhfuss, Proceedings of 5. Kolloquium Mikroproduktion (german), (2015)

11. B. Kuhfuss, E. Moumi, K. Tracht, F. Weikert, F. Vollertsen, A. Stephen, Proceedings $14^{\text {th }}$ ESAFORM, (2011) 